\title{
GESTÃO DAS ÁGUAS PELO CONSELHO ESTADUAL DE RECURSOS HÍDRICOS DE MINAS GERAIS - CERH-MG: ANÁLISE, CLASSIFICAÇÃO E PANORAMA DOS ATOS ADMINISTRATIVOS NOS ÚLTIMOS 20 ANOS
}

\author{
Felipe Silva Marcondes ${ }^{1}$ \\ Simone Magela Moreira²
}

\begin{abstract}
RESUMO
Com o objetivo de avaliar as políticas de gestão das águas no Estado de Minas Gerais pelo Conselho Estadual de Recursos Hídricos (CERH-MG), este estudo situa-se no âmbito da avaliação das instituições participativas sob a ótica estritamente decisória (outputs). Difere, portanto, da análise de causa e efeito entre a publicação de um ato administrativo e o monitoramento ou execução da Política Hídrica (outcomes). Realizado a partir do levantamento censitário das decisões publicadas entre os anos de 1999 e 2019, os atos foram classificados quanto aos instrumentos de gestão a que se referem (1) e quanto às competências atribuídas ao CERH-MG (2). Utilizou-se da técnica de análise documental, em que as categorias são conhecidas a priori, para a classificação dos atos em conjuntos homogêneos e bem delimitados. O estudo elencou 487 atos válidos, sendo 425 atos do tipo aprovativos, os quais são meramente decisórios, e 62 do tipo normativos, cujo objetivo é estabelecer diretrizes e políticas de recursos hídricos. Os atos foram analisados conjuntamente, sendo possível verificar o grau de normatização da implementação da gestão hídrica no estado. Os resultados demonstram uma participação efetiva do CERH-MG na promoção da gestão hídrica. No entanto, verificou-se limitações em sua atuação, principalmente quanto ao enquadramento dos corpos d'água, as penalidades, a compensação financeira a municípios e o rateio de custos das obras de uso múltiplo. Depreende-se do estudo que além da necessidade de uma atuação proativa do $\mathrm{CERH-MG}$, faz-se necessário um desempenho efetivo dos comitês de bacias hidrográficas.
\end{abstract}

Palavras-Chave: Instituições participativas. Conselho de recursos hídricos. Gestão das águas. Instrumentos de gestão. 1 Mestrando em Sustentabilidade e Tecnologias Ambientais pelo Instituto Federal de Minas Gerais
(IFMG), campus Bambuí. Especialista em Gestão Pública (UFJF, 2020). Estatístico (UFMG, 2012). E-
mail: felipesilva81@gmail.com.
2 Professora Dra. no Programa de Pós Graduação em Sustentabilidade e Tecnologias Ambientais do
Instituto Federal de Minas Gerais (IFMG), campus Bambuí. Especialista em Educação (IFMG, 2020).
Doutora em Ciência Animal (UFMG, 2005). Mestre em Epidemiologia e Medicina Veterinária Preventiva
(UFMG, 2001). Graduada em Medicina Veterinária (UFMG, 1995). E-mail: simone.moreira@ifmg.edu.br.

R. gest. sust. ambient., Florianópolis, v. 10, n. 2, p. 150-170, jun. 2021. 


\title{
WATER MANAGEMENT BY THE HYDRICAL STATE RESOURCES COUNCIL OF THE MINAS GERAIS STATE - CERH-MG: ANALYSIS, CLASSIFICATION AND OVERVIEW OF ADMINISTRATIVE ACTS IN THE LAST 20 YEARS
}

\begin{abstract}
In order to evaluate water management policies in the State of Minas Gerais by the State Water Resources Council (CERH-MG), this study is part of the evaluation of participatory institutions from a strictly decision-making perspective (outputs). It differs, therefore, from cause and effect analysis between the publication of an administrative act and the monitoring or execution of the Water Policy (outcomes). Based on the census of decisions published between 1999 and 2019, the acts were classified as to the management instruments to which they refer (1) and as to the competencies attributed to CERH-MG (2). The document analysis technique was used, in which the categories are known a priori, for the classification of the acts into homogeneous and well delimited sets. The study listed 487 valid acts, being 425 acts of the approving type, which are merely decisive, and 62 of the normative type, whose objective is to establish water resources guidelines and policies. The acts were analyzed jointly, being possible to verify the degree of normatization of the implementation of the hydric management in the state. The results demonstrate the effective participation of $\mathrm{CERH}-$ MG in the promotion of water management. However, there were limitations in its performance, especially regarding the framing of water bodies, penalties, financial compensation to municipalities and the apportionment of costs of multiple use works. The study shows that in addition to the need for a proactive action of CERH-MG, an effective performance of the river basin committees is necessary.
\end{abstract}

Keywords: Participatory institutions. Hydrical resources council. Water management. Management tools.

\section{INTRODUÇÃO}

A gestão de recursos hídricos no Brasil foi por muito tempo realizada de forma centralizada e segmentada, em que os governos estaduais e federal centralizavam as decisões para si e segmentavam as diretrizes por setores, tais como energia elétrica, agricultura, saneamento, entre outros (ABERS; JORGE, 2005). O processo de mudança para o que se tem hoje, descentralizado e participativo, iniciou na década de 1980, durante a redemocratização do Brasil.

Neste contexto político, ainda durante o período militar, a participação popular aparece como uma forma de luta contra as injustiças sociais, buscando o seu espaço e inserção nas atividades públicas (LAVALLE, 2011). Sobre estes movimentos sociais de participação popular à época, Gohn (2011) destaca que eles preferiam se manter afastados das estruturas governamentais, pois além delas serem controlados pelo R. gest. sust. ambient., Florianópolis, v. 10, n. 2, p. 150-170, jun. 2021. 
estado militar, a não institucionalização dos movimentos, era uma forma de resistência ao regime.

Após a promulgação da Constituição Federal de 1988 (BRASIL, 1988), a participação popular adquire um novo significado. Lavalle (2011, p. 34), situa a mudança da seguinte forma: "O ideário participativo adquiriu novo perfil no contexto da transição e, mais especificamente, da Constituinte: a participação, outrora popular, tornou-se cidadã." A CF/1988 (BRASIL, 1988) materializou as demandas de participação populares indo além da eleitoral e possibilitou a criação de várias instituições, dentre elas os conselhos de políticas públicas (FARIA; RIBEIRO, 2011). Desta forma, o surgimento dos conselhos após a CF/1988, modifica a estrutura organizacional e a forma de interação entre Estado e sociedade, sinalizando rumo à um novo modelo institucional, mais interativo e participativo (SANTOS; GUGLIANO, 2015).

O surgimento do Conselho Estadual de Recursos Hídricos (CERH-MG) no Estado de Minas Gerais se deu neste período de mudança. O Decreto Estadual no 26.961/1987 (MINAS GERAIS, 1987), o qual cria o CERH-MG, foi publicado um ano antes da promulgação da CF/1988 e, ainda que a intenção de sua criação tenha sido salutar, os mecanismos de participação da sociedade civil eram limitados.

Segundo Tatagiba (2002, apud CUNHA et al., 2011) os conselhos de políticas públicas devem ter basicamente três características que os tornem inovadores, quais sejam, composição diversificada e paritária, serem públicos e com poder deliberativo. Neste sentido, o CERH-MG criado em 1987 possuía pelo menos duas fragilidades: a composição não era paritária e a reunião não era pública. À época, a composição do Conselho, formada apenas por representantes do poder público (artigo $4^{\circ}$ ), contava com a participação da sociedade civil apenas mediante convite do Presidente, conforme artigo 5을 daquele Decreto Estadual (MINAS GERAIS, 1987).

Alves e Souza (2018) caracterizam os conselhos de políticas púbicas como espaços de participação direta da sociedade, sendo, portanto, formas hodiernas de gestão que permitem a inclusão da comunidade na discussão e implementação das políticas. Contudo, o normativo que criou o CERH-MG carecia de melhoras significativas para que se tornasse espaço integrador e democrático.

O período após a Constituição Federal de 1988 até o final da década de 1990 foi marcado pelo empenho em institucionalizar as organizações participativas e R. gest. sust. ambient., Florianópolis, v. 10, n. 2, p. 150-170, jun. 2021. 
principalmente pela consolidação dos mecanismos de participação popular conquistados (GOHN, 2011). Neste ínterim, destaca-se a Lei no 11.504/1994, a qual instituiu pela primeira vez no estado de Minas Gerais a Política Estadual de Recursos Hídricos (MINAS GERAIS, 1994). Algumas unidades federativas, tais como Minas Gerais, São Paulo, Ceará, Bahia e Distrito Federal, editaram as suas normativas hídricas antes mesmo da promulgação, em 1997, da Política Nacional de Recursos Hídricos, seja pela necessidade de uma norma específica para as águas, em função de problemas hídricos, ou para inovação no modelo de gestão, já que a CF/1988 atribuiu aos Estados o direito de legislar sobre as águas superficiais e subterrâneas que estejam sobre seu domínio (BRASIL, 1988; SILVA; HERREROS; BORGES, 2017; COSTA; MERTENS, 2015).

Desta forma, a Política Estadual de Recursos Hídricos (PERH), promulgada em 1994, trouxe importantes avanços, especialmente quanto ao novo modelo de gestão. Instituiu-se o Sistema Estadual de Gerenciamento de Recursos Hídricos (SEGRH-MG), do qual faziam parte o CERH-MG, a Secretaria Executiva, os Comitês de Bacia hidrográfica e as Agências de Bacia hidrográfica. Além disso, sobre os representantes do CERH-MG, trouxe a obrigatoriedade da composição paritária entre o poder público estadual, o poder público municipal, os usuários de água e a sociedade civil (MINAS GERAIS, 1994). Com os novos delineamentos impostos, fezse necessária a edição de um novo normativo, reparando as distorções anteriormente cometidas. Surge, então, o Decreto Estadual n $37.191 / 1995$ que dispõe sobre o CERH-MG, estabelece a equidade de representantes por segmento e, inclui em seu artigo primeiro, a promoção da gestão da política estadual de recursos hídricos como finalidade primordial do Conselho (MINAS GERAIS, 1995).

No entanto, ainda antes de terminar aquela década, foram necessários novos aprimoramentos. A criação da Política Nacional de Recursos Hídricos (PNRH) em 1997, foi um marco na nova forma de gestão das águas, especialmente quando imprimiu em seus fundamentos, a gestão descentralizada por bacia hidrográfica, e participativa, contando com o poder público, os usuários e as comunidades (JACOBI; BARBI, 2007). Consequentemente, muitos Estados editaram suas políticas estaduais de recursos hídricos. Minas Gerais, em 1999, editou a Lei no 13.199 (MINAS GERAIS, 1999) adequando-se aos princípios, diretrizes e fundamentos da $\mathrm{PNRH}$, substituindo a Lei anterior de 1994.

R. gest. sust. ambient., Florianópolis, v. 10, n. 2, p. 150-170, jun. 2021. 
É neste cenário, alguns meses após a promulgação da Política Estadual de Recursos Hídricos (PERH), que o Conselho Estadual de Recursos Hídricos (CERHMG) editou o seu primeiro ato administrativo, a deliberação normativa oㅡ 1/1999 (CONSELHO ESTADUAL DE RECURSOS HÍDRICOS, 1999). Embora tenha sido criado em 1987, a publicação de seu primeiro regimento interno, se deu em 1999, por meio deste ato.

No ano de 2014 foram ainda publicados dois novos normativos relativamente à estrutura, composição e competências do CERH-MG. Primeiro, um novo regimento interno foi estabelecido através da deliberação normativa no 44/2014 (CONSELHO ESTADUAL DE RECURSOS HÍDRICOS, 2014), e alguns meses depois foi publicado o Decreto Estadual no 46.501/2014 (MINAS GERAIS, 2014), o qual está vigente até os dias atuais.

\section{SOBRE A EFETIVIDADE DOS CONSELHOS DE POLÍTICAS PÚBLICAS}

A criação dos conselhos de políticas públicas após a Constituição Federal de 1988 gerou expectativas sobre a participação social na formulação de políticas sobre temas até então exclusivos do Estado. Avaliações iniciais permitiram determinar que muitas organizações participativas acabaram se tornando espaços burocráticos, clientelistas e com vieses de participação (GOHN, 2011). A primeira geração dos estudos sobre tais instituições, entre o final da década 1990 e início dos anos 2000, focou o efeito participativo (ou "não-participativo"), avaliando o processo de aprendizado político e o fortalecimento da democracia. A análise daquilo que era efetivamente produzido por estes Conselhos surge somente em uma segunda geração dos estudos (LAVALLE, 2011; VAZ, 2011). Nesses se considera o amadurecimento na institucionalização dos Conselhos e pressupõe avanços em suas capacidades decisórias.

Dentre as avaliações sobre a efetividade, destacam-se duas linhas, uma interna, sobre a efetividade deliberativa e outra externa, referente à efetividade no cumprimento das políticas públicas. A primeira, se refere à qualidade da participação de seus membros. Sinteticamente, os estudos nessa área investigam a dinâmica do funcionamento das reuniões. Já no campo da efetividade no cumprimento das

R. gest. sust. ambient., Florianópolis, v. 10, n. 2, p. 150-170, jun. 2021. 
políticas públicas, as análises procuram encontrar relações entre causa e efeito, a partir da metodologia de pares contrafactuais (RODRIGUES, 2017).

Relativamente à mensuração de causa e efeito, Lavalle (2011) descreve como uma árdua atividade, tendo em vista que a distância entre a causa e o efeito pode se dar durante um largo espaço de tempo. Desta forma, o autor propõe uma análise específica sobre o processo decisório dos Conselhos, no intuito de tornar a causa e o efeito mais próximos:

[...] fixar o olhar nos efeitos imediatos ou diretamente imputáveis às IPs, naquilo que efetivamente produzem, as decisões, sejam elas consensuais ou conflituosas, a respeito de questões regimentais ou de prioridades de políticas [...]. (LAVALLE, 2011, p. 41).

Desse modo, o presente estudo tem como objetivo analisar os atos administrativos emanados pelo Conselho Estadual de Recursos Hídricos (CERH-MG) nos últimos 20 anos, de modo a oferecer uma apreciação apropinqua da sua capacidade de produção. Neste sentido, a avaliação da promoção da gestão de recursos hídricos será considerada sob a ótica decisória ou deliberativa (outputs). Conferindo, portanto, um benefício que ultrapassa a análise de causa e efeito entre a publicação de um ato administrativo e o monitoramento ou execução da política das águas (outcomes) (LAVALLE; VOIGT; SERAFIM, 2016).

\section{METODOLOGIA}

A pesquisa documental realizada, representa um resgate censitário, à luz de uma perspectiva histórica de todos os atos administrativos do CERH-MG, publicados entre 1999 e 2019. Obtidos por meio de pesquisa eletrônica no portal "Sistema de Informações Ambientais - SIAM", mantido pelo Estado de Minas Gerais (SIAM, 2020), foi objeto de interesse, todos aqueles constantes nos itens "Deliberação CERH-MG" e "Deliberação Normativa CERH-MG". Como este trabalho analítico nunca havia sido realizado, aqueles que eventualmente não constavam no SIAM, tiveram que ser resgatados por meio de pesquisa realizada junto à Imprensa Oficial do Estado de Minas Gerais (IOF), permitindo-se assim, a reunião de todo o material promulgado no período.

R. gest. sust. ambient., Florianópolis, v. 10, n. 2, p. 150-170, jun. 2021. 
No trabalho de pesquisa documental, os documentos inicialmente foram agrupados segundo o tipo de ato administrativo, o número do ato, a data de publicação, a ementa e o endereço eletrônico do ato. Relativamente ao tipo de ato administrativo, salienta-se as deliberações com intuito meramente aprovativas ou decisórias, as quais foram chamadas de Ato Aprovativo, e aquelas deliberações com o objetivo de estabelecer diretrizes e políticas, as quais foram denominadas de Ato Normativo.

Posteriormente, durante o trabalho analítico, as deliberações foram rotuladas quanto à outras duas variáveis que permitiram classificá-las quanto ao instrumento de gestão da Política Estadual de Recursos Hídricos (PERH) a que se refere (1) e à respectiva competência do CERH-MG (2). A categorização dos atos administrativos quanto às estas duas variáveis foi realizada conforme proposto por Bardin (2016), no qual as características dos instrumentos de gestão (1) e das competênias (2) serviram como critérios delimitadores para a classificação, impedindo a duplicidade entre as categorias.

\section{RESULTADOS E DISCUSSÃO}

Desde a sua criação, há 33 anos, o CERH-MG publicou 497 atos administrativos. Desses, foi possível notar inicialmente, que somente 446 (89,7\%) constavam no local onde deveriam ser publicitados, o Sistema de Informações Ambientais (SIAM), tornando necessária uma extenuante pesquisa junto à Imprensa Oficial do Estado (IOF) para que outros $42(10,3 \%)$ documentos fossem engendrados à pesquisa. Nove $(1,8 \%)$ atos foram considerados completamente perdidos e um outro, foi excluído, por se tratar de uma deliberação publicada equivocadamente (Ato Aprovativo no 76/2007) e tornada sem efeito, logo em seguida. Portanto, o estudo considerou, para composição do banco de dados os $487(97,9 \%)$ atos válidos, acessíveis.

Considerando-se a publicidade como princípio constitucional que garante a segurança jurídica, a sua inobservância por parte dos agentes da Administração Pública deve ser corrigida. Dos princípios previstos na Constituição Federal (BRASIL, 1988), se exige a obrigatória divulgação dos atos da Administração Pública, com o objetivo de permitir seu conhecimento e controle pelos órgãos competentes e por toda

R. gest. sust. ambient., Florianópolis, v. 10, n. 2, p. 150-170, jun. 2021. 
a sociedade. A publicidade ser considerada como um meio de preservação da ordem democrática, possibilitando o controle da legalidade e a verificação de sua adequação aos demais valores do Estado. Por isso, a falta de publicidade expõe os atos administrativos à invalidação, por infringir o requisito da moralidade e da eficiência (FREITAS, 2007).

Em períodos históricos, livros e registros materiais eram escassos, frequentemente perdidos ou intencionalmente destruídos. Com a ampliação dos meios de armazenamento e o acesso digital à informação, convencionou-se afirmar que, se, inicialmente o primeiro desafio era o da aquisição, ao longo dos séculos, este foi sendo superado, e conseguir organizar a informação passou a ser a questão mais importante, de forma a promover a recuperação e o seu uso efetivo (ARAUJO, 2009). Por isso, o resgate das publicações da CERH-MG, em bases conceituais, assim como o desenvolvimento de instrumentos mais adequados à sua Representação Documental, constitui oportuna contribuição para a gestão pública.

Dentre 487 atos administrativos disponíveis, 425 (87,3\%) constituem os Atos Aprovativos cuja finalidade foi a aprovação ou a deliberação sobre um tema específico. Apenas $62(12,7 \%)$ são do tipo Ato Normativo, e que efetivamente estabelecem diretrizes ou critérios para a implementação da Política Estadual de Recursos Hídricos (PERH), para o funcionamento de um órgão integrante do Sistema Estadual de Gerenciamento de Recursos Hídricos (SEGRH-MG) ou para o seu próprio funcionamento. Esta discrepância foi também observada por Lavalle, Voigt e Serafim (2016) que consideraram natural o fato de os atos de diretrizes gerais, por sua própria natureza decisória, serem menos frequentes. Isso acontece, pois, a construção de um ato do tipo normativo, envolve um processo minucioso de estudo e proposição de critérios para melhor aderência de uma política, diferentemente do que ocorre com os atos do tipo aprovativos, os quais requerem apenas a decisão sobre um assunto.

Ao longo dos anos, a distribuição dos atos administrativos, segregados por tipo, permite destacar alguns aspectos (Figura 1).

R. gest. sust. ambient., Florianópolis, v. 10, n. 2, p. 150-170, jun. 2021. 
Figura 1 - Número de atos administrativos emitidos de 1999 a 2019

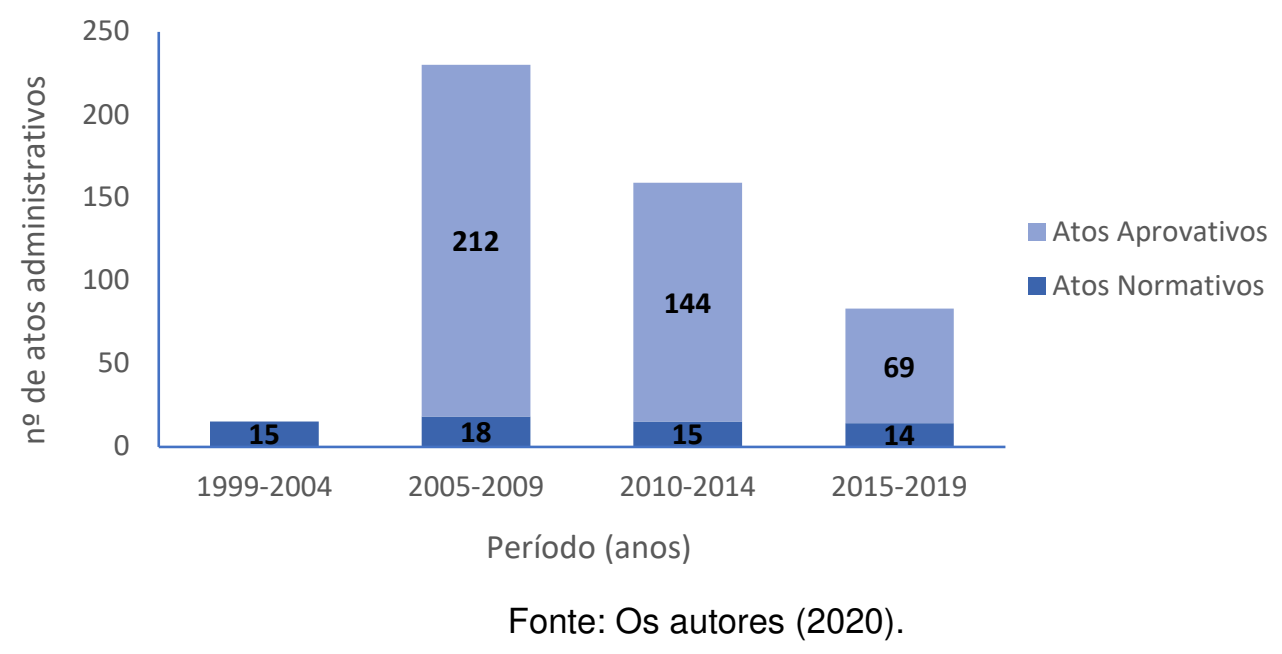

Nos primeiros cinco anos de deliberações administrativas, o Conselho publicou apenas 15 documentos ( $3 \%$ do total), sendo todas de caráter normativo. Dessas, 8 (53,3\%) regulamentam a própria gestão ou a dos Comitês de Bacia. Isso pode ser reflexo de um período inicial, tanto da Política Estadual de Recursos Hídricos (PERH) quanto do CERH-MG, estando ambos, em processo de institucionalização. Nesse período se destaca a primeira etapa de elaboração do Plano Estadual de Recursos Hídricos de Minas Gerais (INSTITUTO MINEIRO DE GESTÃO DAS ÁGUAS, 2006) demonstrando a atuação ainda incipiente do Sistema Estadual de Gerenciamento de Recursos Hídricos (SEGRH-MG) e o estágio inicial dos instrumentos de gestão, contidos na Lei Estadual no 13.1999/1999.

Entre 2005 e 2009, observou-se o pico em volume de produção, com 230 atos (47,2\% do total), sendo 96 destes relacionados aos projetos do Fundo de Recuperação, Proteção e Desenvolvimento Sustentável das Bacias Hidrográficas do Estado de Minas Gerais - FHIDRO. Este resultado representa, por um lado, um período de alta alavancagem nos projetos de recuperação e melhoria dos recursos hídricos, e por outro lado, a necessidade de aprovação destes projetos no CERH-MG, já que o regulamento do FHIDRO exigiu que quaisquer projetos com utilização de recursos não reembolsáveis, antes da aprovação do Plano Estadual de Recursos Hídricos, deveria ser ratificado pelo CERH-MG (MINAS GERAIS, 2006).

Com a aprovação do Plano Estadual de Recursos Hídricos, em 26 de novembro de 2010, os projetos do FHIDRO não mais precisavam passar pelo crivo do $\mathrm{CERH}$ MG, apenas nos casos de omissão do Comitê de Bacia Hidrográfica ou quando o R. gest. sust. ambient., Florianópolis, v. 10, n. 2, p. 150-170, jun. 2021. 
projeto tivesse abrangência estadual (CONSELHO ESTADUAL DE RECURSOS HÍDRICOS, 2010). Isso nos leva a constatar, uma queda no volume de atos administrativos, havendo entre 2010 e 2014 apenas 6 aprovações de projetos do FHIDRO (4 deles antes da aprovação do Plano Estadual de Recursos Hídricos), e entre 2015 e 2019, nenhum outro projeto tendo sido necessária a aprovação pelo CERH-MG.

\subsection{Instrumentos de Gestão}

A classificação dos atos administrativos quanto aos instrumentos de gestão da Política Estadual de Recursos Hídricos (PERH) resultou em um total de 133 (27,3\% do total) deliberações categorizadas (Tabela 1), sendo possível constatar que até o momento não houve quaisquer diretrizes para os instrumentos referentes à "Compensação aos municípios pela exploração e restrição de uso de recursos hídricos" e ao "Rateio de custos das obras de uso múltiplo, de interesse comum ou coletivo". Este resultado sugere a necessidade do estabelecimento de estudos e critérios que subsidiem a implantação destes instrumentos.

Tabela 1 - Distribuição temporal dos atos administrativos, classificados quanto ao instrumento de gestão da Política Estadual de Recursos Hídricos (PERH)

\begin{tabular}{|c|c|c|c|c|c|c|}
\hline \multirow[b]{2}{*}{ Instrumentos de Gestão } & \multicolumn{4}{|c|}{ Distribuição temporal (anos) } & \multirow[b]{2}{*}{ Total } & \multirow[b]{2}{*}{$\%$} \\
\hline & 1999-2004 & $2005-2009$ & $\begin{array}{l}2010- \\
2014\end{array}$ & $2015-2019$ & & \\
\hline $\begin{array}{l}6 \text { - Cobrança pelo uso de } \\
\text { recursos hídricos }\end{array}$ & 0 & 25 & 23 & 6 & 54 & $40,60 \%$ \\
\hline $\begin{array}{l}5 \text { - Outorga dos direitos de uso } \\
\text { de recursos hídricos }\end{array}$ & 3 & 12 & 17 & 5 & 37 & $27,82 \%$ \\
\hline $\begin{array}{l}2 \text { - Planos Diretores de Recursos } \\
\text { Hídricos }\end{array}$ & 0 & 0 & 15 & 1 & 16 & $12,03 \%$ \\
\hline $\begin{array}{l}3 \text { - Sistema Estadual de } \\
\text { Informações sobre Recursos } \\
\text { Hídricos }\end{array}$ & 2 & 2 & 4 & 5 & 13 & $9,77 \%$ \\
\hline $\begin{array}{l}4 \text { - Enquadramento dos corpos } \\
\text { de água }\end{array}$ & 0 & 3 & 0 & 2 & 5 & $3,76 \%$ \\
\hline 9 - As penalidades & 2 & 3 & 0 & 0 & 5 & $3,76 \%$ \\
\hline $\begin{array}{l}1 \text { - Plano Estadual de Recursos } \\
\text { Hídricos }\end{array}$ & 0 & 2 & 1 & 0 & 3 & $2,26 \%$ \\
\hline Total & 7 & 47 & 60 & 19 & 133 & $100,00 \%$ \\
\hline
\end{tabular}

R. gest. sust. ambient., Florianópolis, v. 10, n. 2, p. 150-170, jun. 2021. 
Além desses, outros dois instrumentos da PERH carecem de maior atenção, quais sejam, "Enquadramento dos corpos de água" e "Penalidades". A pequena quantidade de atos alusivos ao primeiro $(5 ; 3,76 \%)$, pode refletir a fragilidade do Sistema Estadual de Gerenciamento de Recursos Hídricos (SEGRH-MG), já que o artigo 43 da Lei Estadual no 13.199/1999 atribuiu ao Comitê de Bacia Hidrográfica, na sua área territorial, a deliberação quanto ao enquadramento e o CERH-MG somente aprovaria após a deliberação desse Comitê. Corroboram esta análise, os dados do Portal Info Hidro (http://portalinfohidro.igam.mg.gov.br/planejamento-de-recursoshidricos) nos quais constam apenas oito bacias hidrográficas com enquadramento aprovado, dentre as 36 unidades de planejamento e gestão em Minas Gerais (INSTITUTO MINEIRO DE GESTÃO DAS ÁGUAS, 2020). No tocante às "Penalidades", destaca-se um ato normativo do CERH-MG no ano de 2003, que estabeleceu critérios para aplicação de multas. Em 2008, houve a criação de um grupo de trabalho para a elaboração de diretrizes para a conversão de multas aplicadas. No entanto, não foram identificados os resultados do trabalho deste grupo. Neste sentido, é possível afirmar que tal instrumento carece de aprimoramentos por parte do $\mathrm{CERH}$ MG.

Outro aspecto que aponta para a vulnerabilidade do SEGRH-MG diz respeito à efetiva implementação do instrumento "Cobrança pelo uso de recursos hídricos". No período de 2005 a 2009, o CERH-MG estabeleceu diversas diretrizes, no entanto, de lá para cá, apenas 12 bacias hidrográficas implementaram a cobrança pelo uso de recursos hídricos, ocorrendo principalmente entre os anos de 2010 e 2014. De forma a reparar este cenário, o CERH-MG criou em 2018 um grupo de trabalho com a finalidade de aprimorar o instrumento e, recentemente, o Estado de Minas Gerais editou o Decreto Estadual № 47.860/2020, que estendeu a cobrança pelo uso de recursos hídricos para as 36 bacias hidrográficas do Estado (MINAS GERAIS, 2020).

Quanto ao instrumento "Outorga dos direitos de uso de recursos hídricos", até o ano de 2014, procedeu-se o estabelecimento de diretrizes gerais para a outorga, bem como atos anteriores à sua concessão, tais como critérios para uso insignificante, atividades minerárias, classificação de empreendimentos, entre outros. Mas, de 2015 a 2019, pouco se obteve em caráter decisório e normatizador. De maneira semelhante, nos demais instrumentos, "Plano Estadual de Recursos Hídricos", "Planos Diretores de Recursos Hídricos" e "Sistema Estadual de Informações sobre 
Recursos Hídricos" observa-se a atuação reduzida do CERH-MG no que tange à normatização destes. Por outro lado, os atos aprobatórios do plano estadual de recursos hídricos e dos planos diretores, principalmente entre 2010 e 2014, ocorreram após demanda específica, originada do poder executivo ou dos Comitês de Bacia.

Estes resultados dificilmente refletem 0 esgotamento da temática correspondente, haja vista as constantes alterações nos cenários estaduais, no que concerne ao uso da água. Mas pode representar sim, um desvio de atenção, dos contextos fáticos que motivam $o$ ato administrativo. $A$ imperiosa exigência entre o que ocorre no mundo real, como elemento motivador do ato administrativo, depende, contudo, que a vontade emane do agente da administração pública (CARVALHO FILHO, 2007). E isso precisa ser examinado, já que, antes de agir concretamente, o Poder Público necessita expedir a declaração de vontade, anunciada por meio das normativas que servem como requisitos legitimadores das atuações futuras.

\subsection{Competências do CERH-MG}

A classificação dos atos administrativos quanto às competências do $\mathrm{CERH}$ MG distribuídas ao longo do período analisado pode ser observada na Tabela 2.

Tabela 2 - Distribuição temporal dos atos administrativos, classificados segundo as competências do CERH-MG

\begin{tabular}{|c|c|c|c|c|c|c|}
\hline \multirow{2}{*}{ Competências do CERH-MG } & \multicolumn{4}{|c|}{ Distribuição temporal (anos) } & \multirow{2}{*}{ Total } & \multirow{2}{*}{$\%$} \\
\hline & $1999-2004$ & $2005-2009$ & $2010-2014$ & 2015-2019 & & \\
\hline $\begin{array}{l}20 \text { - Exercer outras ações, } \\
\text { atividades e funções } \\
\text { estabelecidas em lei ou } \\
\text { regulamento }\end{array}$ & 5 & 74 & 83 & 61 & 223 & $45,79 \%$ \\
\hline $\begin{array}{l}19 \text { - Deliberar sobre recursos do } \\
\text { FHIDRO e relatório de atividades } \\
\text { dos comitês de bacia }\end{array}$ & 0 & 97 & 10 & 1 & 108 & $22,18 \%$ \\
\hline $\begin{array}{l}5 \text { - Estabelecer diretrizes para a } \\
\text { outorga de recursos hídricos }\end{array}$ & 3 & 9 & 14 & 5 & 31 & $6,37 \%$ \\
\hline $\begin{array}{l}6 \text { - Estabelecer diretrizes para a } \\
\text { cobrança pelo uso de recursos } \\
\text { hídricos } \\
1 \text { - Estabelecer diretrizes da }\end{array}$ & 0 & 11 & 10 & 2 & 23 & $4,72 \%$ \\
\hline $\begin{array}{l}\text { PERH, do Plano Estadual e dos } \\
\text { Planos Diretores }\end{array}$ & 4 & 6 & 6 & 5 & 21 & $4,31 \%$ \\
\hline $\begin{array}{l}12 \text { - Aprovar a formação de } \\
\text { Comitês de Bacia }\end{array}$ & 3 & 11 & 4 & 3 & 21 & $4,31 \%$ \\
\hline
\end{tabular}

R. gest. sust. ambient., Florianópolis, v. 10, n. 2, p. 150-170, jun. 2021. 
15 - Aprovar Entidades

Equiparadas à Agência de Bacia

2 - Aprovar o Plano Estadual de Recursos Hídricos

14 - Reconhecer a formação de

Entidades Equiparadas à Agência

de Bacia

8 - Aprovar outorga para

empreendimentos de grande

porte na falta do comitê de bacia

16 - Aprovar o enquadramento

dos corpos de água das bacias

hidrográficas

\begin{tabular}{llllll}
0 & 7 & 10 & 4 & 21 & $4,31 \%$ \\
0 & 2 & 16 & 0 & 18 & $3,70 \%$ \\
0 & 7 & 3 & 0 & 10 & $2,05 \%$ \\
0 & 3 & 3 & 0 & 6 & $1,23 \%$ \\
0 & 3 & 0 & 2 & 5 & $1,03 \%$ \\
15 & 230 & 159 & 83 & 487 & $100,00 \%$ \\
\hline
\end{tabular}

Fonte: Dados da pesquisa (2020).

Nota-se o quantitativo de atos categorizados na competência "Exercer outras ações, atividades e funções estabelecidas em lei ou regulamento", representando $45,79 \%$ (223) de todas as deliberações. Trata-se, em sua maioria (43,53\%), de atos relacionados a autorregulação e autogestão, tais como a instituição de câmaras técnicas, composição de membros, prorrogação de mandatos, entre outros. Este dado é especialmente maior quando analisado no período mais recente, entre 2015 e 2019. No período, foram contabilizados 83 atos, sendo $69,88 \%$ (58) relacionados à autorregulação e autogestão. Isso evidencia uma desproporção entre os atos relacionados ao próprio CERH-MG com as demais atividades decisórias. A autorregulação na qual o órgão regulador atribui ao julgamento e à discricionariedade, o poder de efetuar a supervisão e prevenir violações em suas próprias ações, deve, segundo Trindade e Santos (2009), garantir o afastamento de possíveis inconvenientes como a complacência em relação ao interesse público e à proteção tendenciosa e que necessitam ser completamente evitados.

$\mathrm{Na}$ comparação entre o quantitativo de competências exercidas pelo $\mathrm{CERH}$ MG entre 1999 e 2004, observa-se o cumprimento de apenas quatro das 20 estabelecidas no Decreto Estadual o 46.501/2014, em um montante de apenas 15 atos emitidos. Número bastante inferior ao período seguinte (2005-2009), no qual se verifica o cumprimento de 11 competências em 230 atos publicados. O aumento no número de atos decisórios publicados a partir de 2005, juntamente com a diversificação no cumprimento das competências pode se relacionar ao amadurecimento do CERH-MG. Isso porque, a diversificação quando mantém a proximidade setorial entre a atividade inicial e a atividade visada, constitui importante R. gest. sust. ambient., Florianópolis, v. 10, n. 2, p. 150-170, jun. 2021. 
estratégia relacionada às perspectivas da exploração dos recursos existentes e da aquisição e desenvolvimento de novos conhecimentos e competências (ZARIFIAN, 2001).

Ao longo do período estudado, observou-se que 9 (45\%) das 20 competências atribuídas ao CERH-MG não foram implementadas. Destas, pelo menos três poderiam ser iniciadas pelo CERH-MG, quais sejam, "Aprovar estudos para a compensação a municípios pela exploração e restrição de uso de recursos hídricos", "Propor diretrizes para o rateio de custos das obras de uso múltiplo" e "Aprovar estudos para financiamento ou concessão de subsídios para obras de uso múltiplo de recursos hídricos". A elaboração de estudos e diretrizes citadas acima, poderiam ser levantadas por meio das Câmaras Técnicas especializadas, as quais são criadas pelo CERH-MG e possuem como uma de suas funções a elaboração e encaminhamento de propostas de normas para a legislação hídrica. Neste sentido, nota-se uma inércia na regulamentação destas questões, tanto por parte do CERH-MG como do órgão gestor de recursos hídricos.

A compensação financeira à municípios que tiveram áreas alagadas para a construção de usinas hidrelétricas já é bastante regulamentada e conhecida desde a

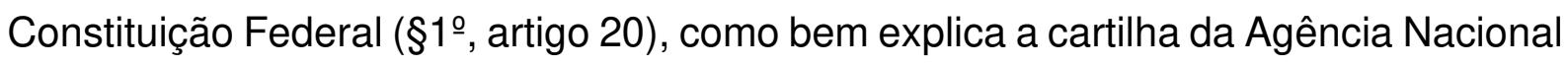
de Energia Elétrica (2007). Entretanto, os cursos d'água estão sujeitos a outras intervenções, seja para a sua exploração ou restrição de uso; e é exatamente a compensação financeira sobre as demais intervenções que se nota a ausência de regulamentação. Neste sentido, o Plano Estadual de Recursos Hídricos de Minas Gerais (INSTITUTO MINEIRO DE GESTÃO DAS ÁGUAS, 2011) aborda sobre a proposta de Pagamentos por Serviços Ambientais (PSAs), extensivo aos municípios que contribuírem positivamente com a preservação do recurso hídrico, seja incentivando atitudes, traçando políticas públicas ou implementando unidades de conservação. Desta forma, a compensação aos municípios não ficaria restrita à apenas grandes obras que interferissem ou se beneficiassem do curso d'água. Portanto, a dotação de valor financeiro à água confere um potencial econômico quando do seu usufruto ou, analogamente, a restrição de sua utilização reduz o poderio econômico. Assim sendo, faz-se necessário que sejam estabelecidas normativas para a devida reparação aos municípios afetados por eventuais restrições ou explorações.

R. gest. sust. ambient., Florianópolis, v. 10, n. 2, p. 150-170, jun. 2021. 
Assim como a compensação aos municípios e a cobrança pelo uso da água, as obras de uso múltiplo de recursos hídricos e o seu rateio são mais um instrumento de mercado. Trata-se de um estímulo à justiça fiscal, pois impõe os custos das obras estruturais, tais como, sistemas de abastecimento, irrigação, projetos de integração, entre outros, aos seus próprios beneficiários. Sabe-se que os valores de realização de tais obras são vultosos, e nada mais justo que seja repartido entre os favorecidos. Desta forma, o rateio de obras de uso múltiplo é um importante instrumento de geração de recursos financeiros, os quais são aplicados na bacia em que foram originados, portanto, a falta de normatização desse instrumento enfraquece a gestão compartilhada de recursos hídricos (SETTI et al., 2000).

\subsection{Panorama de implementação da gestão hídrica}

No que concerne à promoção da gestão hídrica pelo $\mathrm{CERH}-\mathrm{MG}$, pode-se destacar três momentos decisórios distintos: amadurecimento (de 1999 até 2004), intensidade decisória (de 2005 até 2014), redução deliberativa (de 2015 até 2019).

$\mathrm{Na}$ fase de maturação do CERH-MG, entre 1999 e 2004, verificou-se uma atuação focada na institucionalização da Política Estadual de Recursos Hídricos (PERH), em particular quanto ao Sistema Estadual de Gerenciamento de Recursos Hídricos (SEGRH-MG), e de intervenções ainda incipientes sobre a outorga pelo de recursos hídricos e as penalidades previstas na Lei Estadual 13.199/1999.

O segundo momento, ocorrido entre 2005 e 2014, representa o período de maior produção decisória do CERH-MG no que tange à gestão de recursos hídricos (389 atos; 80\%). Houve importantes avanços na normatização da cobrança pelo uso de recursos hídricos e da outorga. Além disso, destaca-se a criação de diretrizes para as Agências de bacias Hidrográficas ou entidades a elas equiparadas, aprovação de projetos de financiamento no âmbito do FHIDRO, de estudos relacionados à gestão de recursos hídricos, de planos diretores de recursos hídricos, do plano estadual de recursos hídricos, entre outras aprovações e normatizações. Não obstante, constatouse pouca expressividade decisória no que concerne ao enquadramento dos corpos de água e às multas e penalidades em infração à legislação de recursos hídricos. Além disso, a análise da produção decisória do CERH-MG permitiu verificar a escassez de aprovação de estudos direcionados à compensação a municípios pela exploração ou

R. gest. sust. ambient., Florianópolis, v. 10, n. 2, p. 150-170, jun. 2021. 
restrição de uso de recursos hídricos, para financiamento ou concessão de subsídios para obras de uso múltiplo de recursos hídricos, bem como diretrizes para o seu rateio.

No último período analisado, entre 2015 e 2019, observou-se uma redução na quantidade de atos administrativos com potencial influência na $\mathrm{PERH}$. Cerca de $70 \%$ dos atos decisórios foram relacionados à autorregulação ou autogestão do CERH$M G$, enquanto que no período total analisado, este índice foi de 43,5\%. Ainda que tenham ocorrido normatizações e aprovações importantes, na maioria das vezes, elas se deram de forma pontual, como por exemplo, o estabelecimento de critérios para a definição de situação de escassez hídrica e restrição de uso da água, ocorrida no ano de 2015, quando o Estado de Minas Gerais atravessava uma crise hídrica (INSTITUTO MINEIRO DE GESTÃO DAS ÁGUAS, 2020b).

Conforme visto, os padrões decisórios do CERH-MG se diversificaram ao longo dos anos. Observou-se em determinado momento e sob alguns instrumentos de gestão, uma atuação contundente. No entanto, relativamente a outros instrumentos sequer houve regulamentação. Sabe-se que a normatização de mecanismos de gestão pode ser iniciada ou incentivada por outros entes do Sistema Estadual de Gerenciamento de Recursos Hídricos (SEGRH-MG), entretanto, espera-se a proatividade e a proposição do CERH-MG, já que é nesta instituição participativa onde se encontram os principais interessados: poder público, usuários e sociedade civil.

\section{CONCLUSÃO}

O levantamento censitário dos atos administrativos emitidos pelo $\mathrm{CERH-MG}$ possibilitou descortinar a distribuição temporal dos atos emitidos por este Conselho desde a sua criação, além de se quantificar os atos de acordo com a sua finalidade. Ademais, a categorização dos referidos atos quanto aos instrumentos de gestão e as competências do CERH-MG permitiu identificar o nível de atenção e normatização sobre os principais assuntos relacionados à gestão de recursos hídricos no Estado de Minas Gerais.

Apesar da efetiva participação do CERH-MG na promoção da gestão hídrica no estado, foram observadas limitações, em particular, quanto ao enquadramento dos corpos d'água, as penalidades, a compensação financeira a municípios e o rateio de custos das obras de uso múltiplo. Vale destacar que, enquanto última instância 
participativa e órgão normativo central, sua atuação depende, muitas vezes, dos comitês de bacias hidrográficas, instâncias colegiadas que atuam em suas respectivas bacias hidrográficas. Assim, para uma maior eficiência, faz-se necessária a atuação integrada do CERH-MG com o órgão gestor e, sobretudo, um desempenho mais expressivo dos comitês cujos problemas necessitam de estudos pormenorizados, para a perspectiva de soluções.

Dentre as barreiras verificadas na promoção da gestão hídrica pelo CERH-MG, destacam-se os assuntos que representam lacunas normativas. Tal deficiência não deve ser atribuída exclusivamente ao CERH-MG, apesar de ser desejável que as câmaras técnicas especializadas deliberem com maior proatividade, antecedendo na elaboração e normatização de abordagens ainda não encetadas pelo Sistema Estadual de Gerenciamento de Recursos Hídricos (SEGRH-MG).

$\mathrm{Na}$ busca pela avaliação da efetividade, o monitoramento dos atos decisórios, analisados isoladamente, não constitui ferramenta típica. No entanto, serve como um importante indicador do modo como a política vem sendo exercida, já que a consumação de determinada norma, quase sempre é precedida pela edição que a idealiza. Portanto, embora haja uma distância entre a publicação de um ato normativo e a sua aplicação no contexto a que se destina, o presente estudo revela evidências dessa articulação como um reminiscente de execução da política.

Por não esgotar a temática, sugere-se que novas pesquisas possam abranger as produções decisórias nas demais instituições participativas de recursos hídricos, ou ainda, se dilatem para monitorar a execução da política hídrica após a promulgação de determinado ato normativo (outcomes), colaborando para o cingir da compreensão.

\section{REFERÊNCIAS}

ABERS, R.; JORGE, K. D. Descentralização da Gestão da Água: Por que os comitês de bacia estão sendo criados? Ambiente \& Sociedade, v. 8, n. 2, p. 99-124, 2005.

ARAUJO, C. A. A. Correntes teóricas da ciência da informação. Ciência da Informação, Brasília, DF, v. 38, n. 3, p.192-204. 2009.

AGÊNCIA NACIONAL DE ENERGIA ELÉTRICA. A compensação financeira e o seu município. Brasília: ANEEL, 2007, 27 p.

R. gest. sust. ambient., Florianópolis, v. 10, n. 2, p. 150-170, jun. 2021. 
ALVES, F; SOUZA, M. Democracia participativa: os conselhos gestores de políticas públicas como mecanismo de participação popular. Argumenta Journal Law, n. 28. p. 107-124, 2018.

ANDRADE, A.; ROSSETI J. P. Governança corporativa: fundamentos, desenvolvimento e tendências. $5^{\mathrm{a}}$ ed. São Paulo: Ed. Atlas, 2011, 596 p.

BARDIN, L. Análise de Conteúdo. 1ª ed. São Paulo: Edições 70, 2016, 279 p.

BRASIL. [Constituição (1988)]. Constituição da República Federativa do Brasil de 1988. Brasília, DF: Presidência da República, 1988. Disponível em:

http://www.planalto.gov.br/ccivil_03/constituicao/constituicaocompilado.htm. Acesso em: Acesso em: 22 out. 2020.

BRASIL. Lei no 9.433, de 8 de janeiro de 1997. Institui a Política Nacional de Recursos Hídricos [...]. Brasília, DF: Presidência da República, 1997. Disponível em: http://www.planalto.gov.br/ccivil_03/LEIS/L9433.htm. Acesso em: Acesso em: 22 abr. 2020.

CARDOZO, J. E. M. Princípios constitucionais da administração pública (de acordo com a Emenda Constitucional n.. 19/98). In: MORAES, A. Os 10 anos da Constituição Federal. São Paulo: Editora Atlas, 1999.

CARNEIRO, C. B. L. Conselhos de políticas públicas: desafios para sua institucionalização. Revista de Administração Pública, v. 36, n. 2, p. 277-292, 2002.

CARVALHO FILHO, J. S. Manual de Direito Administrativo. 18 ed. rev. ampl. e atual. Rio de Janeiro: Lumen Juris, 2007, 92 p.

CONSELHO ESTADUAL DE RECURSOS HÍDRICOS (CERH-MG). Deliberação Normativa $n^{\circ}$ 1, de 17 de agosto de 1999 (revogada). Estabelece o Regimento Interno do Conselho Estadual de Recursos Hídricos - CERH-MG. Minas Gerais, 1999. Disponível em: http://www.siam.mg.gov.br/sla/download.pdf?idNorma=32836. Acesso em: 22 abr. 2020.

CONSELHO ESTADUAL DE RECURSOS HÍDRICOS (CERH-MG). Deliberação CERH-MG no 260, de 26 de novembro de 2010. Aprova o Plano Estadual de Recursos Hídricos do Estado de Minas Gerais. Minas Gerais, 2010. Disponível em: http://www.siam.mg.gov.br/sla/download.pdf?idNorma=15394. Acesso em: 18 ago. 2020.

CONSELHO ESTADUAL DE RECURSOS HÍDRICOS (CERH-MG). Deliberação Normativa $n^{\circ} 44$, de 6 de janeiro de 2014. Estabelece o Regimento Interno do Conselho Estadual de Recursos Hídricos - CERH/MG. Minas Gerais, 2014. Disponível em: http://www.siam.mg.gov.br/sla/download.pdf?idNorma=31675. Acesso em: 22 abr. 2020.

COSTA, A. L; MERTENS, F. Governança, redes e capital social no plenário do Conselho Nacional de Recursos Hídricos do Brasil. Ambiente \& Sociedade, v. 18, n. 3, p. 153-170, 2015.

R. gest. sust. ambient., Florianópolis, v. 10, n. 2, p. 150-170, jun. 2021. 
CUNHA, E. S. M; ALMEIDA, D. C. R; FARIA, C. F; RIBEIRO, U. C. Uma estratégia multidimensional de avaliação dos conselhos de políticas: dinâmica deliberativa, desenho institucional [...] In: PIRES, R. R. C (org.), Efetividade das Instituições Participativas no Brasil: Estratégias de Avaliação. Brasília: Ipea, 2011, p. 125-135.

FARIA, C. F; RIBEIRO, U. C. Desenho Institucional: Variáveis relevantes e seus efeitos sobre o processo participativo. In: PIRES, R. R. C (org.), Efetividade das Instituições Participativas no Brasil: Estratégias de Avaliação. Brasília: Ipea, 2011, p. 125-135.

FREITAS, N. J. Ato administrativo. Belo Horizonte: Editora Fórum, 2007.

FUJITA, M. S. L. A Identificação de Conceitos no Processo de Análise de Assunto para Indexação. Revista Digital de Biblioteconomia e Ciência da Informação, v. 1, n. 1, p. 60-90, 2003.

GOHN, M. D. G. Participação de representantes da sociedade civil na esfera pública na América Latina. Política \& Sociedade, v. 10, n. 18, p.223-244, 2011.

INSTITUTO MINEIRO DE GESTÃO DAS ÁGUAS. Plano Estadual de Recursos Hídricos de Minas Gerais. Relatório final - Consolidação da $1^{1 \underline{a}}$ etapa do Plano Estadual de Recursos Hídricos. 2006. Disponível em:

http://www.igam.mg.gov.br/images/stories/PERH/perhnet.pdf. Acesso em: 15 mai. 2020.

INSTITUTO MINEIRO DE GESTÃO DAS ÁGUAS. Plano Estadual de Recursos Hídricos - PERH. Relatório final - volume II: instrumentos de gestão de recursos hídricos. Belo Horizonte: IGAM, 2011, 348 p.

INSTITUTO MINEIRO DE GESTÃO DAS ÁGUAS. Portal Info Hidro, Planejamento de Recursos Hídricos. 2020a. Disponível em:

http://portalinfohidro.igam.mg.gov.br/planejamento-de-recursos-hidricos. Acesso em: 26 abr. 2020.

INSTITUTO MINEIRO DE GESTÃO DAS ÁGUAS. Escassez Hídrica. 2020b. Disponível em: http://www.igam.mg.gov.br/component/content/article/16/1553escassez-hidrica. Acesso em: 14 mai. 2020.

JACOBI, P. R.; BARBI, F. Democracia e participação na gestão dos recursos hídricos no Brasil. Revista Katálysis, v. 10, n. 2, p. 237-244, 2007.

LAVALLE, A. G. Participação: valor, utilidade, efeitos e causa. In: PIRES, R. R. C (org.), Efetividade das Instituições Participativas no Brasil: Estratégias de Avaliação. Brasília: Ipea, 2011, p. 33-41.

LAVALLE, A. G.; VOIGT, J.; SERAFIM, L. O que Fazem os Conselhos e Quando o Fazem? Padrões Decisórios e o Debate dos Efeitos das Instituições Participativas. Dados - Revista de Ciências Sociais, v. 59, n. 3, p. 609-650, 2016. 
MINAS GERAIS. Decreto no 26.961, de 28 de abril de 1987. Cria o Conselho Estadual de Recursos Hídricos, CERHI. Minas Gerais: Diário Oficial do Estado de Minas Gerais, 29 abr. 1987.

MINAS GERAIS. Decreto no 37.191, de 28 de agosto de 1995 (revogado). Dispõe sobre o Conselho Estadual de Recursos Hídricos - CERH-MG - e dá outras providências. Minas Gerais: Diário Oficial do Estado de Minas Gerais, 29 ago. 1995.

MINAS GERAIS. Decreto $n^{\circ} 41.578$, de 8 de março de 2001. Regulamenta a Lei $n^{\circ}$ 13.199, de 29 de janeiro de 1999, que dispõe sobre Política Estadual de Recursos Hídricos. Minas Gerais: Diário Oficial do Estado de Minas Gerais, 9 mar. 2001.

MINAS GERAIS. Decreto $n^{\circ} 44.314$, de 7 de junho de 2006. Contém o Regulamento do Fundo de Recuperação, Proteção e Desenvolvimento Sustentável das Bacias Hidrográficas do Estado de Minas Gerais - FHIDRO. Minas Gerais: Diário Oficial do Estado de Minas Gerais, 8 jun. 2006.

MINAS GERAIS. Decreto $n^{\circ} 46.501$, de 5 de maio de 2014. Dispõe sobre o Conselho Estadual de Recursos Hídricos - CERH-MG. Minas Gerais: Diário Oficial do Estado de Minas Gerais, 6 mai. 2014.

MINAS GERAIS. Decreto $n^{\circ} 47.960$, de 7 de fevereiro de 2020. Dispõe sobre a implantação da Cobrança pelo uso de Recursos Hídricos no Estado e dá outra providência. Minas Gerais: Diário Oficial do Estado de Minas Gerais, 8 fev. 2020.

MINAS GERAIS. Lei no 11.504, de 20 de junho de 1994 (revogada). Dispõe sobre a Política Estadual de Recursos Hídricos e dá outras providências. Minas Gerais: Diário Oficial do Estado de Minas Gerais, 21 jun. 1994.

MINAS GERAIS. Lei no 13.199, de 29 de janeiro de 1999. Dispõe sobre a Política Estadual de Recursos Hídricos e dá outras providências. Minas Gerais: Diário Oficial do Estado de Minas Gerais, 30 jan. 1999.

RODRIGUES, F. P. A efetividade dos conselhos municipais de habitação: mecanismos entre decisão e implementação. Dissertação (Mestrado em Ciência Política) - Universidade de São Paulo, São Paulo, 2017.

SANTOS, P. R.; GUGLIANO, A. A. Efetividade das políticas participativas no governo brasileiro: O Conselho de Desenvolvimento Econômico e Social. Revista de Sociologia e Politica, v. 23, n. 56, p. 3-19, 2015.

SETTI, A. A.; LIMA, J. E. F. W.; CHAVES, A. G. M.; PEREIRA, I. C. Introdução ao Gerenciamento de Recursos Hídricos. $2^{\underline{a}}$ ed. Brasília: ANEEL, 2000, 207 p.

SIAM. Sistema de Informações Ambientais. Secretaria de Estado de Meio Ambiente e Desenvolvimento Sustentável, Legislação Ambiental, 2020. Disponível em: http://www.siam.mg.gov.br/sla/action/Consulta.do. Acesso em: 26 abr. 2020. 
SILVA, M. B; HERREROS, M. M. A. G; BORGES, F. Q. Gestão integrada dos recursos hídricos como política de gerenciamento das águas no Brasil. Revista de Administração da Universidade Federal de Santa Maria, v. 10, n. 1, p. 101-115, 2017.

SOUSA, B. P.; FUJITA, M. S. L. Análise de assunto no processo de indexação: um percurso entre teoria e norma. Informação e Sociedade, v. 24, n. 1, p. 19-34, 2014.

TEIXEIRA, L.; SILVA, J.; LIMA, H. Administração no sistema prisional - um estudo das competências gerenciais. Contextus-Revista Contemporânea de Economia e Gestão, v. 9, n. 2, p. 55-67, 2011.

TRINDADE, M; SANTOS, A. M. Regulação e Autorregulação no Brasil e a crise internacional. Espaço Jurídico BM\&FBOVESPA, 2009. Disponível em: https://www.bsmsupervisao.com.br/assets/file/BSM-Artigo-MarceloTrindade-eAlineMenezesSantos.pdf. Acesso em: 13 mai. 2020.

VAZ, A. C. N. Da Participação à Qualidade da Deliberação em Fóruns Públicos: 0 Itinerário sobre Conselhos no Brasil. In: PIRES, R. R. C (org.), Efetividade das Instituições Participativas no Brasil: Estratégias de Avaliação. Brasília: Ipea, 2011, p. 91-107.

ZARIFIAN, P. Objetivo Competência: por uma nova lógica. São Paulo: Atlas, 2001, $197 \mathrm{p}$. 